Inj Prev. 2016 June ; 22(3): 226-229. doi:10.1136/injuryprev-2015-041838.

\title{
Injury prevention as social change
}

\author{
R J McClure ${ }^{1}$, K Mack ${ }^{1}$, N Wilkins ${ }^{1}$, and T M Davey ${ }^{2}$ \\ ${ }^{1}$ National Center for Injury Prevention and Control, Centers for Disease Control and Prevention, \\ Atlanta, Georgia, USA; \\ ${ }^{2}$ School of Public Health, University of Queensland, Brisbane, Queensland, Australia
}

\section{INTRODUCTION}

We will not solve the public health problem of injury simply by educating individuals about the nature of injury risk, improving their risk assessment and providing these individuals with information to enable them to reduce the level of risk to which they are exposed. Substantial improvement in the societal injury burden will occur only when changes are made at the societal level that focus on reducing the population-level indicators of injury. ${ }^{12}$ The shift from an individual to a population perspective has substantial implications for the way we perceive, direct, undertake, and evaluate injury prevention research and practice. The analogy of 'the population as patient' provides a clear illustration of the foundational truths that underpin the preferred public health approach to the prevention of injury.

Society is the system within which populations exist. Sustained change made at the societal level to reduce population-level indicators of injury morbidity and mortality involves systemic change. In this paper, we consider a shift from the contemporary systematic approach to unintentional injury and violence prevention, ${ }^{3}$ to a systemic approach ${ }^{4}$ more consistent with the principles of ecological public health. ${ }^{5}$ We consider the extent to which the logic of the systematic model, and the related misconceptions about the role of uncertainty in science, limit local, national and global efforts to minimise injury-related harm. We explore the implications of a systemic perspective for the field of injury prevention and conclude by delineating a new programme of work that could be of considerable benefit to the injury-related health of populations.

\section{Individual risk versus population frequency}

Should there be a perceived benefit of engaging in a risky driving behaviour, a person on a given day could double her or his risk of death without noticing the change in their

\footnotetext{
Correspondence to Dr Roderick John McClure, Division of Analysis, Research and Practice Integration (DARPI), National Center for Injury Prevention and Control, Centers for Disease Control and Prevention, 4770 Buford Highway NE, MS F-62, Atlanta, GA 30341, USA; rmcclure@cdc.gov.

Contributors

All authors were equally involved in all aspects of the conceptualisation and writing of this manuscript.

Publisher's Disclaimer: Disclaimer The findings and conclusions in this manuscript are those of the authors and do not necessarily represent the views of the Centers for Disease Control and Prevention.

Competing interests None declared.

Provenance and peer review Not commissioned; externally peer reviewed.
} 
likelihood of dying on the road. If, on that day, the person sustains no adverse consequence from his or her risky driving behaviour, the person's tendency to take that risk again would be reinforced. However, in a city, state or nation with a population of 10 million people, and 11.8 RTC deaths per 100000 person years that increase in population fatal crash risk by 0.000118 would result in three extra deaths in that population per day, and 1179 deaths extra for the year. Furthermore, a person who moves from Sweden, where there is an estimated national RTC fatality rate of 2.8 per 100000 per year, ${ }^{6}$ to South Africa where there is an estimated rate of 25.1 deaths per 100000 per year, ${ }^{6}$ dramatically increases their personal risk of injury, even if they do not consciously change their driving behaviour-simply because they are changing the context within which their driving occurs.

If we understand causation of injury at the individual level, and the problem in the population as an aggregation of individual risk, we are dealing with abstract risks and probabilities and the transient nature of individual-level risk factors. If we understand prevention of injury in terms of individual risk assessment and acceptance, then prevention requires intervention at the level of every risk calculation people make. This approach has serious limitations in that, first, it assumes people actually do continually make those rational risk calculations throughout their day, and second, it ignores the fact, illustrated by the above example, that at the individual level, the rational answer frequently falls in favour of increasing the small individual risk in order to achieve certainty of gaining the benefit of the moment.

On the other hand, if we talk in terms of frequencies of deaths in a population, the problem of injury can be more clearly understood, more rationally debated and more easily addressed. The relationships between probabilities, objective and subjective risk assessment, and potential effects of individualised behaviour change, can be hard to cognitively operationalise. However, when expressed as bald population frequencies, these numbers represent the facts to which potential solutions can be pegged, decisions made and societies held accountable.

Perhaps the most compelling benefit of the 'population as patient' approach is that it provides a clear scope for injury prevention and a means by which prevention goals can be achieved. While we may not know enough to cure a disease, we do know enough to at least shift the health of the least healthy populations to match that of the healthiest. ${ }^{7}$ All countries of the world have access to the same evidence base to support technical and behavioural solutions for RTC injury, yet the RTC death rate in some populations is 10 times the rate in others. ${ }^{67}$ When setting out to halve the global road toll, ${ }^{8}$ the first step is to recognise that the occurrence of disease and injury reflects the circumstances of society as a whole. ${ }^{78}$ There is tremendous opportunity for reduction in RTC injury that can be achieved by bringing the road transportation system of the highest risk populations into line with transport systems already existent in populations of lowest risk. Public health approaches to unintentional injury and violence prevention should not be merely educating individuals about their own individual risk, but instead should focus on putting in place changes to the system that are required if lives are to be saved. 
The argument that is usually made against collective responsibility is the rights based argument, which asserts individuals have a right to decide whether or not they want to wear a seat belt, or speed, or use a cellphone while driving. An individual may say 'I have a right to drive as I wish and choose the level of risk I am prepared to take, and I need laws that allow me the freedom to do so,' but a transportation system designed to protect that right would be inherently more dangerous, not just for that individual but for all users. The reason for this is that people actually do not make rational risk calculations on a continuing basis throughout their daily lives because of the impossibly large cognitive load that would entail. ${ }^{9}$ Instead they use mental short-cuts (heuristics) to aid their decision making. ${ }^{9}$ Transportation safety laws and regulations are designed to encourage appropriate road user decisions by entrenching a set of universal heuristics. The road user can replace a large part of the costbenefit calculations involved in driving with one heuristic, that is, 'following the road rules,' that simplifies the driving experience for all and reduces the ambient levels of risk inherent in the system. A transportation system regulated such that it allows an individual to decide on a situation-by-situation basis whether they want or do not want to increase their personal risk, is a transportation system in which the risk to all users is increased and innocent lives will be lost.

\section{The systematic versus systemic model of injury causation and prevention}

The public health approach to injury prevention is usually described in terms of a linear systematic process. It begins with an elucidation of the nature and extent of the injury problem. Proximal risk and protective factors are then identified. Countermeasures, and strategies for implementing the countermeasures, are generated to address the modifiable risk factors. The efficacy of the countermeasures and strategies are quantified, and interventions developed to create programmes for implementation to target groups in controlled settings. If found to be effective in these circumscribed settings, the programmes are deemed to be evidenced-based programmes ready for 'scaling up' to the population level.

Implicit in the systematic model of injury prevention is the notion that proximal risk factors can be isolated from their contexts; interventions to address these risk factors can be developed and tested; and that knowledge of the interventions leads to reduced injury-related morbidity and mortality. The prevention process based upon the systematic approach favours the selection of a specific target injury type in an area where the mechanisms for the injury can be clearly delineated, and where knowledge about countermeasures for these mechanisms can be succinctly summarised and appropriately disseminated.

At the heart of the systematic model of injury prevention are Newtonian principles of energy exchange. ${ }^{3}$ Like Newtonian physics, the systematic model of injury causation and approach to prevention of injury is valid only within the limited boundaries defined for the model. It assumes a person's individual risk is the sum or product of factors in a linear causal pathway where people act independently of other individuals in society. In replacing the bounded truths of Newton with a more general theory of relativity, Einstein's work highlights the importance of appropriately matching the frames of reference of an explanatory model with the purpose for which the model is used. People do not believe, behave or act as independent 
entities, but as members of societies, and in societies it is frequently the interaction between the components that determines the nature, extent and direction of progress. Organic relationships are more frequently exponential than linear and feedback loops and homoeostatic mechanisms keep things in balance until tipping points occur. ${ }^{1011}$ Social change is achieved by restricting growth in one direction and encouraging growth in another, not by replacing one existent reality with its counterfactual. The assumptions on which the systematic model of injury prevention is based are not consistent with the environments in which these models are expected to perform.

A model of injury prevention at the population level would need to account for the problem of injury within, not outside of, the societal context in which it occurs. ${ }^{12}$ Societies are constantly changing, with tightly coupled components, non-linear relationships, and history dependent status. They are self-organising, adaptive and evolving, operationalised through trade-offs, counterintuitive and policy resistant. In possessing these attributes, societies define themselves to be complex systems. ${ }^{11}$

A systemic intervention capable of achieving sustained population-level change is designed and built from the ground up within the institutions and infrastructures that define society's form and function. While many interventions contain components that are built in a 'laboratory,' a societal intervention is always of orders of magnitude larger than any of its component parts, and always dependent on the societal governance, resourcing, engagement and context in order to operationalise any of its research-tested elements.

In their state-of-the-art account, Eliminating serious injury and death from road transport, ${ }^{14}$ Johnson and colleagues provide a clear illustration of the systemic nature of effective injury efforts and the ineffectiveness of an approach focusing just on component causes.

Highlighting the results of a European study ${ }^{13}$ that explained the success of Sweden, the UK and the Netherlands in their efforts to reduce motor vehicle death rates, Johnson and colleagues argue that effective prevention is more about how societies go about addressing the motor vehicle injury problem rather than about the package of risk factor countermeasures they choose. ${ }^{13}$ The efficacy of seat belts, speed limits or roadside crash barriers, can be quantified in research settings, but these countermeasures can never comprise a motor vehicle safety solution on their own. These components can only influence population-level RTC mortality and morbidity if incorporated into a larger intervention that includes a strong public demand for change, committed societal leadership, a climate of safety, an appropriate infrastructure, cooperation and coordination between all stakeholders, and a long-term perspective from all. ${ }^{12}$ These additional elements are social institutions that exist in the world, not in controlled research settings.

Thus, as illustrated by the above example, effective injury prevention solutions are built from the ground up in the public domain, not in a research environment and multiplied to scale. Injury prevention is achieved by making those changes in society's form and function that lead to downstream reductions in the population prevalence of the proximal risk factors for injury. 
Without cultural change we will remain locked into a process of making only incremental improvements. To achieve cultural change we need to understand how to influence social change at a macro level. ${ }^{13}$

\section{The principle of the drunkard's search}

Much of the current support for the systematic model comes from a misplaced understanding of the nature and role of uncertainty in science. ${ }^{15-17}$ The mantra of modern medicine (and associated public health, policy and resource allocation activities) is the importance of implementing only evidence-based interventions. Evidence-based interventions are those that have been demonstrated to have an effect in research studies designed and conducted in such a way that the effect estimates are precise, and chance and bias do not threaten the validity of the study findings. We completely agree with the goal of implementing evidence-based interventions. However, it might be time to consider whether the search for an evidence base has become simply a search for certainty.

Studies that are currently defined as providing the highest level evidence are actually not studies that provide the highest level of evidence, but studies that provide the highest level of certainty. ${ }^{18}$ The actual evidence obtained might be exceedingly trivial, and yet still of high 'quality' according to the existing evidence base taxonomy. The evidence on which population-level injury prevention depends, is evidence that exists in the real world at the population level. Given the limitations of what can actually be examined in highly controlled experiments in research settings, this search for certainty has resulted in more and more research about topics more and more removed from what we need to drive injury prevention. If only those intervention components that can be isolated for testing through randomised controlled trials under circumscribed conditions, with the individual as the unit of analysis, can be considered 'quality,' then while we may be certain about the study results, the results tell us little about the effectiveness of the overall population-based intervention. ${ }^{19-23}$

The evidence base to support injury prevention at the population level needs to cover community engagement, local contexts, measurement of unintended consequences, feedback loops, the relationship between intervention components, and the connections between arealevel and individual-level causes and effects. There is no question that population-level interventions need to be based on the highest-level science. The challenge is to develop science in this societal space, rather than depend on the science currently developed for use in the controlled environment of 'laboratory' experiments. ${ }^{2425}$

It is a fact that we live with uncertainty, in science and in life; 'As far as the laws of mathematics refer to reality, they are not certain, as far as they are certain, they do not refer to reality'. ${ }^{26}$ The issue for scientists, and decision makers, is how to accommodate uncertainty into one's interpretations of the observed world and our consequent decisions. We do not eradicate uncertainty about an intervention's effect by isolating only those components that can be controlled, and then testing the efficacy of those components. Finding certainty in the laboratory simply ignores the consequent uncertainty of how the product functions in the world outside the laboratory where the intervention belongs. Attempting to eradicate uncertainty by conducting randomised controlled trials on components of an intervention simply moves that uncertainty into the phase of 
implementation effectiveness, and our overall level of uncertainty in the value of our intervention remains unchanged.

Again, the 'population as patient' analogy is instructive. Clinical medicine understands the human organism to be a complex system-of-systems generally held in homoeostatic equilibrium by the properties of each of the systems and the relationship between them. Thus 'in vitro' research undertaken in test tubes is not considered to be best evidence as the results 'in vitro' often differ from the 'in vivo' evidence obtained from holistic observations of the fully working human body. By analogy it is in the fully working society that the effectiveness of injury interventions need to be judged, as the results there are not logically predicted from observations made on isolated randomised controlled trials of component parts.

\section{So what does all this mean for the field of injury prevention?}

Replacing the systematic approach with a systemic one has three implications for the field of injury prevention. The first for injury research, the second for injury prevention practice, and the third for the role of injury prevention within the institutions that make up our society.

In the past, injury prevention researchers have prized the pursuit of knowledge in abstract research settings and following the manner described by Karl Popper, asked 'why not'. ${ }^{27}$ The task now is to look at what is the real world and ask why. The frequencies of injuries in a population is facts, not inferences or estimates. They exist. Differences in rates between populations are real differences, and in a deterministic world there are by definition, real causes for the differences between rates. The causes lie in differences in the societal institutions, practices and infrastructures between the populations, not in the differences between people. At the population level, human nature is the same all over the world. Where differences lie, are between the systems within which people live; and it is in the differences between these systems that the answer to the causal questions can be found. Once causes are identified, population-solutions to the public health problem that is injury become clearly evident.

Systems research studies is just as much a scientific concern as are randomised controlled trials. Rigour in the philosophy and practice of science is no less important in either stream. However, in all science we need to keep remembering that the properly formulated research question comes first, then the appropriate scientific method to address the question is chosen second. We should not first choose to use a hammer then find the only thing we can then do to build the house of evidence is knock in the nails. Elucidating the components of the systems responsible for the different injury rates between populations is a scientific exercise. 2425 There is still little research in the area of population-level change. If we have the methods to do that now, we should use them. If the scientific methods to do so are not yet available at a sufficient level or rigour, then we need to develop the methods, not change the question. In these last two sentences lies the research challenge of the systemic approach to prevention.

Injury prevention is currently based on the energy transfer definition of injury. ${ }^{3}$ Derived from the infectious disease model and operationalised at the individual level, it overtly 
avoids notions of accountability and outcome. In accordance with this definition, funders support injury prevention activity in areas where the mechanisms for a type of injury can be clearly delineated, and where knowledge about countermeasures for these mechanisms can be succinctly summarised and appropriately disseminated. A population approach to prevention, on the other hand, suggests a definition of injury prevention that is systemsfocused, outcomes-driven, grounded in accountability and ubiquitously applicable; that is,

.the optimal governance and functioning of individuals within their social and physical environments in circumstances where human well-being is an essential performance requirement expected of all institutions, organisations and citizens. ${ }^{4}$

In contradistinction to the systematic approach, prevention practice at the systemic level requires a collective vision for an agreed common good; a long-term, strategic plan for achieving that agreed outcome; commitment from all involved to work on what needs to be done to achieve that goal; implementation of what is known; and development of new knowledge on the basis of changes observed. In this sentence is the challenge of the systemic approach for practitioners.

So what would injury prevention look like if the field responded as suggested and shifted more towards systemic solutions measured in terms of population-level reductions in injury morbidity and mortality? The result would be alarming and deeply rewarding, and would take considerable courage.

Injury prevention as a field would partially devolve throughout the more general universal approach to improving societies' form and function. In doing so it would become more centrally located within existing social and medical establishments; and in being more centrally located it would lose some of its injury-specific identity and assume more the mantle of societal improvement. Yes, this would change the way we see ourselves, and the way we do business; but it would change for the better. Injury prevention specialists would be just as needed as we now are, but we would become part of a bigger framework that comprised a more compelling solution.

\section{REFERENCES}

1. Mack KA, Liller KD, Baldwin G, et al. Preventing unintentional injuries in the home using the Health Impact Pyramid. Health Educ Behav 2015;42 (1 Suppl):115S-22S. http://www.swov.nl/ rappor...wer_plus6_Final_Report.pdf [PubMed: 25829110]

2. Mercy J, Mack K, Steenkamp M. Changing the social environment to prevent injury In: Doll L, Bonzo S, Mercy J, et al., eds. Handbook of injury and violence prevention. New York, NY: Springer, 2007:277-94.

3. Haddon W On the escape of tigers: an ecologic note. Am J Public Health Nations Health 1970;60:2229-34.

4. McClure RJ. On living with Tigers: an ecological post script. J Health Saf Res Pract 2012;4:1-7.

5. Rayner G, Lang T. Ecological public health reshaping the conditions for good health. London, UK: Routledge, 2012.

6. Global status report on road safety 2015. Geneva: World Health Organization, 2015.

7. Rose G The strategy of preventive medicine. Oxford, UK: Oxford University Press, 2012. 
8. United Nations Department of Economic and Social Affairs. Partnerships for sustainable development goals. Geneva: United Nations, 2015 https://sustainabledevelopment.un.org/content/ documents/211617\%20Goals\%2017\%20Partnerships.pdf (accessed 30 Oct 2015).

9. McLucas AC. Decision making: risk management, systems thinking, and situation awareness. Canberra, ACT: Argos Press, 2003.

10. Gladwell M The tipping point: how little things can make a big difference. New York, NY: Little, Brown and Company, 2000.

11. Sterman JD. Learning from evidence in a complex world. Am J Public Health 2006;96:505-14. [PubMed: 16449579]

12. Moller J Reconsidering community based interventions. Inj Prev 2004;10:2-3. [PubMed: 14760018]

13. Johnson IR, Muir C, Howard EW. Eliminating serious injury and death from road transport: a crisis of complacency. Boca Raton, FL: CRC press, 2014.

14. Wegman F, Eksler V, Hayes S, et al. eds. SUNflower +6 A comparative study of the development of road safety in the SUNflower+6 countries: final report, Leidschendam, NL: SWOV, 2005.

15. Kaplan A The conduct of inquiry: methodology for behavioral science. New Brunswick, NJ: Transaction Publishers, 1998;11.

16. Pruyt E, Willem L, Auping WL, et al. Ebola in West Africa: model-based exploration of social psychological effects and interventions. Syst Res Behav Sci 2015;32:2-14.

17. Pruyt E State of Art versus State of Science of Integrated Risk-Capability Analysis under Deep Uncertainty Third International Engineering Systems Symposium CESUN 2012. Delft University of Technology, 18-20 62012.

18. Guyatt GH, Sackett DL, Sinclair JC, et al. Users' guides to the medical literature. IX. A method for grading health care recommendations. Evidence-Based Medicine Working Group. JAMA 1995;274:1800-4. [PubMed: 7500513]

19. World Health Organisation. Health promotion evaluations: recommendations to policy-makers A report of the WHO European Working Group on Health Promotion Evaluation. Copenhagen, DK: WHO, 1998.

20. Rychetnik L, Frommer M, Hawe P, et al. Criteria for evaluating evidence on public health interventions. J Epidemiol Community Health 2002;56:119-27. [PubMed: 11812811]

21. Sanson-Fisher RW, Bonevski B, Green LW, et al. Limitations of the randomized controlled trial in evaluating population-based health interventions. Am J Prev Med 2007;33:155-61. [PubMed: 17673104]

22. Gilligan C, Sanson-Fisher R, Shakeshaft A. Appropriate research designs for evaluating community-level alcohol interventions: what next? Alcohol Alcohol 2010;45:481-7. [PubMed: 20610639]

23. Rivara F Evaluating the effect of an injury prevention intervention in a population. Am J Prev Med 2008;34:S148-52. [PubMed: 18374266]

24. Biglan A, Ary D, Wagenaar AC. The value of interrupted time-series experiments for community intervention research. Prev Sci 2000;1:321-49.

25. Hawkins NG, Sanson-Fisher RW, Shakeshaft A, et al. The multiple baseline design for evaluating population-based research. Am J Prev Med 2007;33:162-8. [PubMed: 17673105]

26. Einstein A Geometry and experience. Berlin, DE: Springer, 1921.

27. Popper K Logik der Forschung. Vienna, AT: Springer, 1935. 